October 16, M. Cheradame (of the Centre d'Etudes et Recherches des Charbonnages de France) gave an insight into somo of the problems affecting the production of coke in France, and described the resoarches which his organization had undertaken in an effort to solve them. For many years the French have found it difficult to use certain of their indigenous coals to produce a coke suitable for the blast furnace. Hence, a major task facing the research organization of the nationalized French coal industry has been the investigation of means for producing a good metallurgical coke from the highly swelling coals of the Lorraine, where most of France's iron ore occurs. M. Cheradame recalled that early research into cokemaking was largely of an empirical kind. Since 1950, however, basic researches carried out at the Verneuil Laboratories had been supplemented by practical tests on full-scale ovens erected for the purpose at Marienau in the Lorraine coal field. In M. Cheradame's view, three main ideas would dominate future research on coking. These were, first, that the chemical use of hard coal in the form of metallurgical coke was advantageous and should be developed; second, that anthracite and, more generally, smokeless fuels should be used for solid fuel domestic heating ; and third, that the range of coals which could be coked corresponded, in many countries, to too small a proportion of coal output and should be extended.

\section{World Directory of Crystallographers}

ThE Philips Laboratories of Irvington-on-Hudson have recently published a "World Directory of Crystallographers" compiled by Dr. W. Parrish. It lists the names, titles, places of graduate study, addresses and fields of interest of 2,260 crystallographers in fifty-four countries; a preface includes $a$ brief statistical analysis of this information. Much credit is due to Dr. Parrish for his initiative and industry in preparing this work, and to Messrs. Philips for their encouragement and generous contribution to editorial and clerical expenses. Inevitably the first edition suffers from omissions and other shortcomings, but it is satisfactory to learn that if support is adequate the Directory will be published at regular intervals by the International Union of Crystallography. Copies may be obtained at a price of 1.50 dollars post paid from Polycrystal Book Service, 84 Livingston Street, Brooklyn 1, New York.

\section{Philips Gas Refrigerating Machine}

The new Philips P.W.7000 gas refrigerating machine is now available (cf. Nature, 176, 623; 1955). It is a compact, electrically driven, singlecylinder unit, capable of producing five litres of liquid air or liquid nitrogen an hour within $15 \mathrm{~min}$. of starting up. The design of the equipment is unique in that the gas to be liquefied does not undergo compression or pass through any working parts; by this means an exceptionally pure product is assured. The machine will produce liquid gas from those gases which will liquefy at above $-200^{\circ} \mathrm{C}$, and temperatures of $-80^{\circ}$ C. to $-200^{\circ}$ C. can be achieved in a single stage. Under normal conditions, the machine requires only an hour for defrosting and draining of the freezer after 16-20 hr. production. Moisture and carbon dioxide are removed simply by freezing.

\section{Acceleration of Life-cycle of Southern Pine}

$A_{N}$ important advance in scientific forestry may be marked by experiments at the California Institute of Technology in which the life-cycle of pine trees has been accelerated more than five-fold. In the Earhart Plant Laboratory, seedlings of the southern pine, commercially the most important pulp wood in the United States, have flowered (produced cones) in a period of only two years. In the forest, this process takes 12-15 years. Selected seeds from single trees of the southern pine were planted in the Earhart Laboratory, where various climatic conditions can be reproduced and controlled. Some of the seeds were placed in conditions of continuous summer, so that the seedlings grew rapidly. Some were planted under conditions of alternate winter and summer, so that several yearly growth cycles were completed in each 12-month period. Finally, some of the treos were first grown to large size in continuous summer, then given a long winter period of dormancy before being returned to summer conditions in which they resumed their growth. 'Two years after the seeds were planted, this third group of trees produced three female flowers, or pine cones. This is believed to be the first deliberate induction of flowering in a pine tree. The fact that cones have been produced in the southerm pine in two years instead of the usual 12-15 years means that it may now be possible to hybridize the trees through repoated generations in the timespan of a single human generation. This will greatly speed up the breeding of trees for faster growth, for better wood, for resistance to diseases and pests, and for growth in climates where they do not now grow.

\section{Pink Shrimps and Red Prawns}

Since the War, prawns of the genus Pandalus have been increasing in commercial importance. Earlier in the century they were scarcely fished, since the major grounds of most species of this genus lie in deep water, but modern boats and tackle have made their exploitation feasible. Recently, two important works on the biology and fishery of species of Pandalus have appeared. Both species, like most but not all of the species of Pandaloidea which have been investigated, are protandric hermaphrodites, but whereas in $P$. borealis all individuals apparently reverse sex from male to female (a fact which has been attracting some experimental studies recently), in $P$. montagui ( $F i s h$. Invest., Lond., Ser. 2, 21, No. 4; 1957) Mistakidis has shown that there is a proportion, about 30 per cent, which are primary females, showing no sex reversal. $P$. montagui is unusual too in inhabiting, during part of the year, shallow inshore waters, in the Thames Estuary and Morecambe Bay, so that the fishery is of long standing. The fishery for $P$. borealis, on the contrary, is recent and rapidly expanding, and Horsted and Smidt have presented an extensive study of the actual and potential fishery in Greenland waters, with accounts of the natural history of the prawn and of the fishing grounds in Greenland (Medd. Komm. Havundersog., Kbh., New Ser., 1, No. 11 ; 1956).

\section{Exhibition of Nature Photography}

THE Royal Photographic Society's annual autumn Exhibition of Nature Photography will be opened at 16 Princes Gate, London, S.W.7, at 4 p.m. on November 28 by Mr. David Attenborough. It will be open to the public during November 29December 20 (not Sundays). The Exhibition will 